symptoms of polycythaemia vera the plate that illustrated the paper in the Arch. of Ophthal. has been excellently reproduced with the kind permission of the editors of that journal. The only other illustration is one showing the details of Calhoun's operation for glaucoma. We doubt whether this was worth reproducing, all the more as its value has yet to be established. The task of selecting articles of sufficient value and novelty for a work of this kind is a very arduous one and one that necessitates much miscellaneous reading in various foreign languages. Colonel Lister is to be congratulated on the successful results of his work.

\title{
CORRESPONDENCE
}

\section{TWO CURIOUS OPTICAL ILLUSIONS}

\section{To the Editor of The British Journal of Ophthalmology}

SIR,-I discovered the two following illusions by accident, and as they have as far as I know, never been mentioned before, I think they may prove of interest to your readers.

The first illusion may be seen by anybody in almost any restaurant and I consider that it forms a proof of Listing's Law. As some of your readers may not be familiar with this law I will briefly describe it. If we sit down in front of a white wall at a little distance, say ten to twenty feet, and first fix a bright red vertical cross on the wall in front, in such a position that when our line of sight is at right angles to the wall, it shall be directly in front of us, the visual field will be determined for the direction of fixation. This is far from being evident $a$ priori, since it might be supposed that the eyeball is capable of rotation round its visual axis. But this never occurs except within a small angle not exceeding two or at the most three degrees. So long as the head is kept rigidly in a vertical position, the eyes may roll in any direction, but the cross will always assume a vertical position, and not incline at all. But if we turn the head away from the primary position either upwards or downwards, or sideways, to what we may call a secondary position, and then keeping the head in that position, we gaze steadily at the cross for some moments, so as to obtain an after image in the complementary colour, and then turn the eyes directly upwards or downwards, and keep them quite still, we shall find that the cross still remains upright as before, but 
directly we turn the eyes sideways from this secondary position, the cross appears to have turned partly round through about 30 degrees to the right (ar left) as the case may be. So that there is only one position of the head in which the cross remains erect,

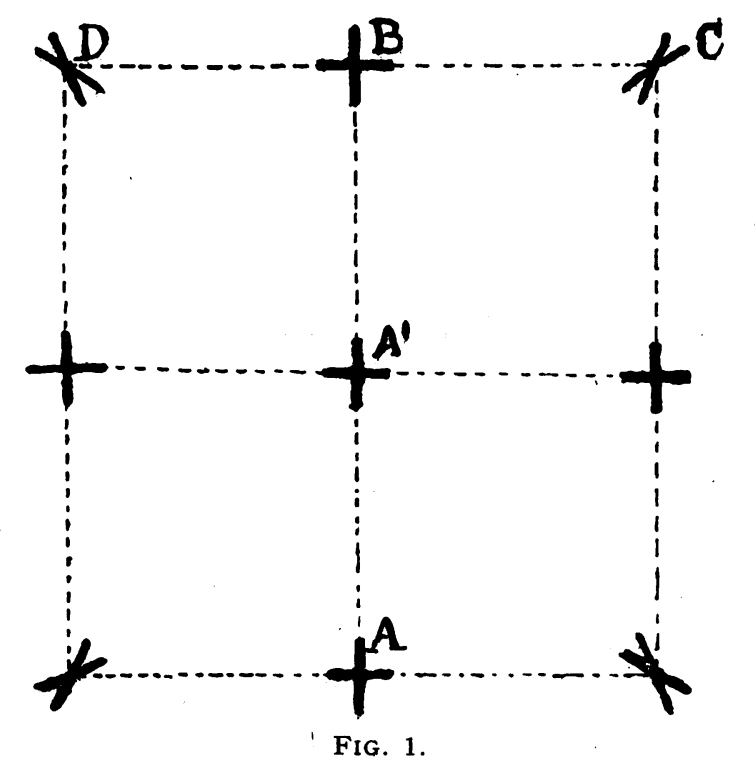

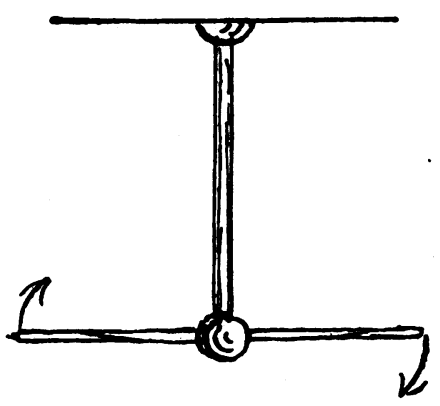

FIG. 2.

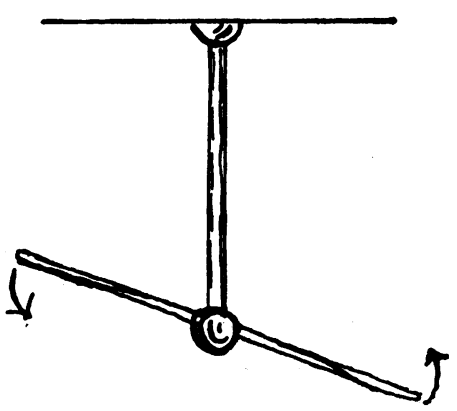

FIG. 3.

since for every other position the cross turns partly round. This then is the Law of Listing.

Now if we look at a ventilator fan, having two or four blades, such as can be found in almost any restaurant, which should be placed at a. considerably higher level than the eye, and we sit down about fifteen or twenty feet from it, and then raise our eyes so as to look at it in a vague manner (i.e., without fixing or 
focussing our eyes) in the direction of any spot about two or three yards above and to the right of the ventilator, the fans which were revolving clockwise, will now appear to revolve in the opposite direction, and to be tilted downwards and outwards, at an angle approximately 30 degrees from the horizontal plane.

I have tried this experiment hundreds of times, as have a number of my friends, and we have found this invariably to be the case. I think the experiment can readily be explained by Listing's Law, but the reason why the fans appear to revolve in the opposite direction is due to another cause, and the solution is I think due to the fact that the centre of rotation is not the same as the nodal point, or points (for they are so close together that they may be considered as one) but is situated $5 \mathrm{~mm}$. behind it, i.e., nearer to the retina. This causes movements of objects out of the primary line of regard to appear to turn in the opposite direction when the head is no longer in the primary position. But this may not be the true explanation, although it seems to me to explain the phenomenon fairly well, and I cannot find any other rational explanation for it.

The second optical illusion is as follows :

If you look at any isolated raised spot, about the size of a pin's head, or a little larger (and such spots formed by tiny blobs of whitewash or paint are very numerous on any white wall) and gaze at this white spot at your normal reading distance, and then raise your head slowly, and at the same time look vaguely without focussing your eyes on anything, the spot will appear to travel in an irregular fashion upwards, exactly as any insect would do. In fact this illusion is sometimes so perfect as to deceive one into thinking that the spot is really an insect. But the moment one fixes one's eyes on to the spot the illusion at once disappears and the spot ceases to move, and its real nature becomes apparent. I think that this apparent movement is likewise due to the fact that the eye after it has been raised, will slowly but unconsciously droop, thus causing the back of the eye, and with it the macula, to rise, and so the spot appears to run up the wall in an irregular manner. This latter very important fact, namely, that the eye does move in tiny jerks, and not in a steady sweep, was first discovered by Dr. Mulder, an ophthalmic surgeon practising in Durban, Natal, and repeated experiments on myself have confirmed his observations in the fullest manner.

Yours truly,

Geo. Lindsay Johnson.

DURBan. 